\title{
ALTERNATIVE MODEL TO DETERMINE THE CHARACTERISTIC STRENGTH VALUE OF WOOD IN THE COMPRESSION PARALLEL TO THE GRAIN
}

\author{
André Luis Christoforo ${ }^{1}$, Vinicius Borges de Moura Aquino ${ }^{2, ↔}$, José Silvio Govone ${ }^{3}$, \\ Alfredo Manuel Pereira Geraldes Dias ${ }^{4}$, Tulio Hallak Panzera ${ }^{5}$, Francisco Antonio Rocco Lahr ${ }^{6}$
}

\begin{abstract}
Wood strength values are calculated based on the characteristic value, which corresponds to the $5 \%$ percentile of a given probability distribution model. For a few number of samples (12 samples), the Brazilian standard establishes an estimator of the characteristic compressive strength parallel to grain of the wood, which may provide a different result when compared with the characteristic value coming from a suitable probability distribution model. Considering the strength results in the parallel compression to the grain of 45 wood species of the hardwood group, Normal, LogNormal, Weibull and Exponential probability distribution models were used for each specie with the purpose of determining the one with the highest adhesion. Calculated the characteristic values by the best probability model distribution, an analysis of variance (ANOVA) was performed in the estimation of the characteristic value of compressive strength, making it possible to identify the most significant terms of the models as well as the quality of the adjustment obtained on such models. The proposed regression model $\left(\mathrm{R}^{2}\right.$ adj $\left.=96,56 \%\right)$ proved to be equivalent to the empirical model of the Brazilian standard. The model proposed here only depends on the mean and the lowest value obtained from the compressive strength in the parallel direction to the grain.
\end{abstract}

Keywords: Characteristic value, mechanical properties, probability distribution, Tabebuia spp., wood.

\section{INTRODUCTION}

The wood, a natural and renewable source material, presents a good relation between mechanical strength and density (Arruda et al. 2015, Baar et al. 2015, Cavalheiro et al. 2016), which makes it suitable for use in construction (Andrade Jr. et al. 2014, Chen and Guo 2017, Lahr et al. 2017).

Brazil is a country with enormous potential for timber applications, since the availability of wood species from the Amazon Forest is the order of 11194 wood species, cataloged between the years 1707 and 2015 (Steege et al. 2016) these conditions motivated the development of new researches with the purpose of characterizing new species to replace those commonly used in civil construction (Ferro et al. 2015, Freitas et al. 2016, Almeida et al. 2016, Christoforo et al. 2017).

\footnotetext{
${ }^{1}$ Department of Civil Engineering, Federal University of São Carlos, São Carlos, São Paulo, Brazil.

${ }^{2}$ Araguaia Engineering Institute, Federal University of Southern and Southeastern Pará, Santana do Araguaia, Pará, Brazil.

${ }^{3}$ Department of Statistics, Applied Mathematics and Computation, Center of Enviromental Studies, State University of São Paulo, Rio Claro, São Paulo, Brazil.

${ }^{4}$ Department of Civil Engineering, University of Coimbra, Coimbra, Portugal.

${ }^{5}$ Department of Mechanical Engineering, Federal University of São João del-Rey, São João del-Rey, Minas Gerais, Brazil.

${ }^{6}$ Department of Structures Engineering, University of São Paulo, São Carlos, São Paulo, Brazil.

•Corresponding author: aquino.vini@hotmail.com

Received: 21.01.2019 Accepted: 25.02.2020
} 
In Brazil, timber structures projects are regulated by the Brazilian Standard ABNT NBR 7190 (1997) "Wood Structures Project", and the structures are designed assuming small displacements and therefore the principle of geometric linearity and also to withstand satisfactorily and safely the action of the acting forces.

For reasons of structural design safety, the values of strength to the mechanical stresses of the wood are obtained based on the characteristic value (and not on the mean value), which corresponds to the $5 \%$ percentile of the respective probability distribution.

According to the probabilistic method of the Brazilian standard ABNT NBR 7190 (1997), a normal distribution is assumed of the strength values. Such hypothesis is based on the consideration of large number of samples (30 or more test specimens) together with a value limit of $18 \%$ of the coefficient of variation. Given the average value of the strength $(\bar{f})$ and its standard deviation (sd), the characteristic value $\left(f_{w k}\right)$ of the property is determined using Equation 1.

$$
f_{w k}=\bar{f}-1,645 x s d
$$

For a small number $(\mathrm{n})$ of samples $(\mathrm{n}<30)$, the Brazilian standard establishes the use of Equation 2 to estimate the characteristic strength value.

$$
f_{w k}=\left(2 \frac{f_{1}+f_{2}+f_{2}+\ldots+f_{(n / 2)-1}}{(n / 2)-1}-f_{n} / 2\right) \times 1,10
$$

From Equation 2, $n$ is the number of samples used in the mechanical tests and $f_{i}$ consists of the strength values of the sample, and the results must be arranged in ascending order $\left(f_{1} \leq f_{2} \leq f_{3} \ldots \leq f_{n}\right)$, neglecting the largest value of the strength if the number of specimens is odd and not assumed to be less than $f$ and not less than $70 \%$ of the average value of the strength. It should be noted that the Brazilian standard ABNT NBR 7190 (1997) establishes 12 specimens for determining the physical and mechanical properties of the wood, and that, therefore, the characteristic value is calculated based on twelve strength values.

The adoption of Equation 2 for the estimation of the characteristic value can result in values different from the characteristic value associated to a certain probability density function, and it should be noted that there are several existing probability density functions (Pinto et al. 2004), and found the one of best adherence to the set of strength values, it can obtain the characteristic value with greater reliability. Being higher than the characteristic value estimated by the expression of the standard in relation to that obtained by a given model of probability distribution, this implies in the possibility of overestimating the strength of the wood, condition usually unfavorable to the project, and of underestimating it otherwise, which motivates the development of researches in this area.

This research aimed to identify the characteristic value $\left(f_{c 0, k}\right)$ per wood specie associated with the best probability distribution model and relate, using a multilinear regression model, with the mean values, coefficients of variation and with the lowest and highest value of the property per species, using four probability distribution models (Normal, LogNormal, Weibull and Exponential) and 45 species of wood from the group of hardwood. By the adjusted coefficient of determination $\left(\mathrm{R}^{2}\right)$ obtained from the regression model, it will be possible to evaluate the precision in the estimation of the characteristic value of $f_{c 0, k}$, a precision that is unknown with the use of Equation 2 established by the Brazilian standard. 


\section{MATERIAL AND METHODS}

The values of strength in compression parallel to the grain $\left(f_{c 0}\right)$ of the wood were obtained following the assumptions and the methods of testing and calculation of the Brazilian standard ABNT NBR 7190 (1997) on its Annex B. Twelve specimens were manufactured and tested for each wood species, from which were obtained the mean values, the highest and the lowest values, the coefficient of variation, the standard deviation and also the characteristic values, the latter determined by Equation 2 (Brazilian standard) and the probability distribution models.

The 45 species of wood used in the development of this project were: Angelim Amargoso (Vatairea fusca); Angelim Araroba (Vataireopsis araroba); Angelim Ferro (Hymenolobium sp.); Angelim Pedra (Hymenolobium petraeum); Angelim Saia (Dinizia excelsa); Angelim Vermelho (Dinizia excelsa Ducke); Angico Branco (Anadenanthera colubrina); Angico Preto (Piptadenia macrocarpa); Branquilho (Terminalia sp.); Cafearana (Andira sp.); Cambará Rosa (Erisma sp.); Canafístula (Cássia ferruginea Schrad); Casca Grossa (Ocotea odorifera); Castanheira (Bertholletia excelsa); Castelo (Gossypiospermum praecox); Catanudo (Calophyllum sp.); Cedro Amargo (Cedrela odorata); Cedro Doce (Cedrela sp.); Cedroarana (Cedrelinga cateniformis Ducke); Champanhe (Dipteryx odorata (Aublet.) Willd); Copaíba (Copaifera sp.); Cutiúba (Copaifera sp.); Garapa (Apuleia leiocarpa); Goiabão (Planchonella pachycarpa); Guaiçara (Luetzelbburgia sp.); Guajará (Micropholis venulosai); Guarucaia (Peltophorum vogelianum); Itaúba (Mezilaurus itauba); Jatobá (Hymenea sp.); Louro Preto (Ocotea sp.); Louro Verde (Laurus nobilis); Maçaranduba (Manilkara sp.); Mandioqueira (Qualea sp.); Oiticica Amarela (Clarisia racemosa); Oiuchu (Rapanea sp.); Parinari (Parinari rodolph Huber); Pauóleo (Copaifera sp.); Piolho (Tapirira guianesis); Quarubarana (Erisma uncinatum); Quina Rosa (Chinchona sp); Rabo de Arraia (Vochysia sp.); Sucupira (Diplotropis sp.); Tachi (Tachinalia sp.); Tatajuba (Bagassa guianensis) and Umirana (Qualea retusa). It should be noted that they were tested with moisture content close to $12 \%$, which consists of equilibrium moisture content according to the Brazilian standard.

The probability distributions considered in this research to determine the characteristic values were Normal, LogNormal, Weibull and Exponential, whose probability density functions $(f)$ on the random variable $\mathrm{X}$ are expressed in Equation 3, Equation 4, Equation 5 and Equation 6, respectively.

$$
\begin{gathered}
f(x)=\frac{1}{\sqrt{2 \pi \sigma^{2}}} e^{-1 / 2\left(\frac{x-\mu}{\sigma}\right)^{2}}, x \in(-\infty, \infty) \\
f(x)=\left\{\begin{array}{l}
\frac{1}{x \sigma \sqrt{2 \pi}} e^{-1 / 2\left(\frac{\log (x)-\mu}{\sigma^{2}}\right)^{2}}, \text { if } x>0 \\
0, \text { otherwise }
\end{array}\right. \\
f(x)=\left\{\begin{array}{l}
\frac{\delta}{\alpha^{\delta}} x^{\delta-1} e^{-\left(\frac{x}{\alpha}\right)^{\delta}}, \text { if } x \geq 0 \\
0 \text { if } x<0
\end{array}\right. \\
f(x)=\left\{\begin{array}{l}
\lambda e^{-\lambda x}, x \geq 0 \\
0 \text { if } x<0
\end{array}\right.
\end{gathered}
$$

From Equation 3, $\sigma$ and $\mu$ consist of the standard deviation and the population mean, respectively. In Equation $4, \sigma$ is the standard deviation and $\mu$ is the population mean of the logarithm. From the Weibull probability density function (Equation 5), $\delta$ and $\alpha$ are the form and scale parameters, respectively, and $\lambda$ is the Exponential 
function distribution rate parameter (Equation 6).

The adhesion tests (at the $95 \%$ level of reliability) used to verify the best distribution model were obtained by the Least Squares Method, with the aid of Minitab ${ }^{\circledR}$ software version 18.

The characteristic values of each wood species $\left(f_{c 0, k}\right)$ for distribution models suitable probability were obtained, these results were related to the mean value $\left(\mathrm{x}_{\mathrm{m}}\right)$, coefficient of variation $(\mathrm{CV})$, the smallest (Min) and highest (Max) value of $f_{c 0}$ by means of a multilinear regression model (Equation 7) evaluated based on analysis of variance (ANOVA), at the level of $5 \%$ of significance, whose quality of fit was evaluated by means of the adjusted coefficient of determination $\left(\mathrm{R}^{2} \mathrm{adj}\right)$.

$$
f_{c 0, k}(M P a)=\beta_{0}+\beta_{1} x_{m}+\beta_{2} C V+\beta_{3} M i n+\beta_{4} M a x+\varepsilon
$$

From Equation 7, $\beta_{i}$ consist of the coefficients adjusted by the least square method and $\varepsilon$ is the random error. By the ANOVA formulation of the regression model, P-value (Probability P) equal to or greater than the significance level (5\%) implies in the model or its coefficients are not representative (null hypothesis $\mathrm{H}_{0}$ - factor variations do not explain the variations in dependent variable), and significant otherwise (alternative hypothesis $\mathrm{H}_{1}$ - $\mathrm{P}$-value $<0,05$ ).

Because twelve specimens were used to determine the characteristic strength value by both Equation 2 and the probability distribution models, the Equation 7 should strictly consider a maximum of 12 values.

The Anderson-Darling test (Weerahandi 1995) was used to evaluate the normality in the ANOVA residue distribution of the regression models, and the graph of residuals versus fitted values was used to assess the homogeneity of the residues, making possible validate the results of the analysis of variance.

The multilinear regression model was compared with the empirical model (Equation 2) proposed by the Brazilian standard, allowing to evaluate the precision of the model proposed in this standard.

\section{RESULTS AND DISCUSSION}

The confidence interval (CI) of the mean (at the $5 \%$ level of significance) for $f_{c o, k}$ calculated by the Brazilian standard equation resulted in IC $=(49,74 ; 60,28 \mathrm{MPa})$, being $31,90 \%$ the coefficient of variation obtained. The values of the compressive strength parallel to the grain determined by the standard ranged from $25,52 \mathrm{MPa}$ to $96,58 \mathrm{MPa}$, thus evidencing the coverage of the results due to all strength classes for the hardwood group were accounted for.

The confidence interval (CI) of the mean (at the $5 \%$ level of significance) for $f_{c 0, k}$ calculated by the probability distribution models resulted in $\mathrm{CI}=(45,88 ; 55,56 \mathrm{MPa}), 31,77 \%$ coefficient of variation obtained. The lowest and the highest value of the property were equal to $19,32 \mathrm{MPa}$ and $85,50 \mathrm{MPa}$, respectively.

From 45 wood species evaluated by the probability distribution models in $f_{c 0, k}, 40 \%(18 / 45)$ of the species were better represented by the LogNormal model, 17,78 \% (8/45) were better adjusted by the Normal distribution model and 42,22\% (19/45) by the Weibull model, and it should be noted that the Exponential model did not provide a significant adjustment for $f_{c 0, k}$ in any of the evaluated species. Even though the Normal probability distribution model was not the one with the best adhesion, yet all the wood species presented Normal distribution, a result that favors the use of the empirical equation of the Brazilian standard.

The regression model for estimating the characteristic value of resistance in compression parallel to the grain is expressed by Equation 8, and the results of ANOVA and their validation (normality, independence and homogeneity of variances) are presented in Table 1 and in Figure 1, respectively.

$$
\begin{gathered}
f_{c 0, k}(M P a)=-1,21+0,49 x_{m}-0,04 C V+0,67 \text { Min }-0,16 \text { Max } \\
{\left[R^{2} \text { adj }=97,08 \%\right]}
\end{gathered}
$$


Table 1: Results of the ANOVA of the regression model.

\begin{tabular}{|c|c|c|c|c|c|}
\hline Source & GL & SQ (Aj.) & QM (Aj.) & F-Value & P-Value \\
\hline Regression & 4 & 11123,1 & 2780,78 & 366,79 & 0,000 \\
\hline $\mathrm{x}_{\mathrm{m}}$ & 1 & 62,0 & 61,96 & 8,17 & 0,007 \\
\hline $\mathrm{CV}$ & 1 & 0,4 & 0,43 & 0,06 & 0,813 \\
\hline Mín & 1 & 1627,5 & 1627,49 & 214,67 & 0,000 \\
\hline Máx & 1 & 8,4 & 8,41 & 1,11 & 0,298 \\
\hline Error & 40 & 303,3 & 7,58 & & \\
\hline Fault of adjust & 39 & 303,1 & 7,77 & 46,20 & 0,116 \\
\hline Pure error & 1 & 0,2 & 0,17 & $*$ & $*$ \\
\hline Total & 44 & 11426,4 & & & \\
\hline
\end{tabular}

* GL - freedom degrees, SQ(Aj) - sum of squares; QM(Aj) - mean squares.

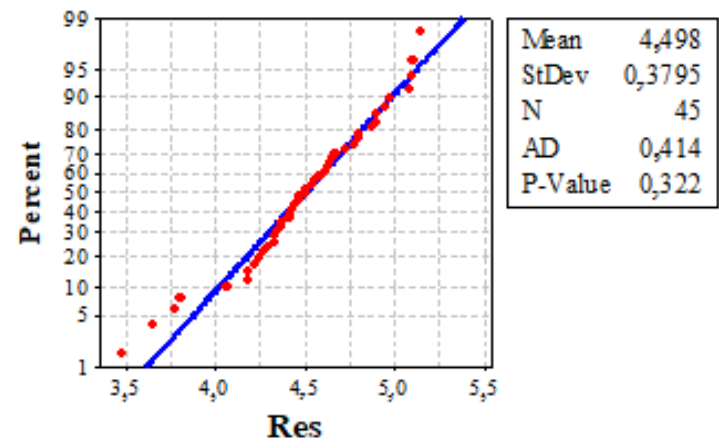

Figure 1: Anderson-Darling normality test of residues for ANOVA validation.

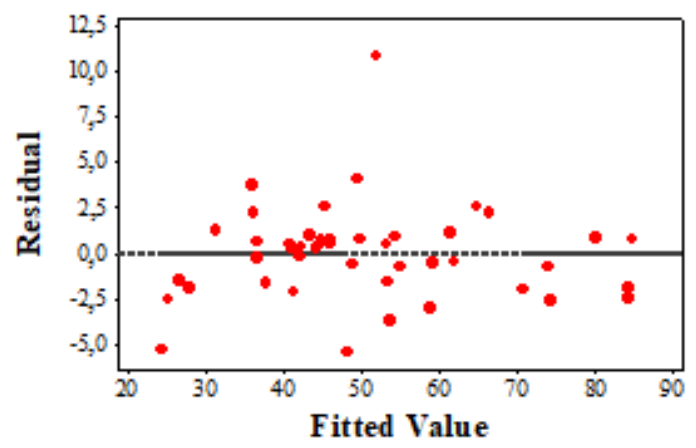

Figure 2: Residue graph versus adjusted values for ANOVA validation.

Figure 1 shows normality in the distribution of residues (P-value $>0,05)$, and Figure 2 shows that residues (randomly distributed) are grouped around 0 (evidence of homogeneity of variances), thus validating the model of ANOVA. It should be noted that the three points located at -5 and at +10 on the axis of the ordinates (Res) in the graph of Figure 2 are considered as outliers, and that ended up impacting negatively the quality of the adjustment, but they were preserved in order to conserve the variability in the wood physical and mechanical properties (Christoforo et al. 2017). 
Table 1 shows that the regression model obtained was significant ( $\mathrm{P}$-value $<0,05$ ), with a good accuracy of the adjustment by the adjusted coefficient of determination (97,08\%). From the coefficients of the model, only the mean $\left(\mathrm{x}_{\mathrm{m}}\right)$ and the lower value of the compressive strength parallel to the grain $\left(f_{c 0}\right)$ significantly affected the characteristic values $\left(f_{c o, k}\right)$ of compressive strength parallel to the grain, implying that the coefficient of variation $(\mathrm{Cv})$ and the highest value (Max) of $f_{c 0}$ have little effect on the estimate of $f_{c 0, k}$.

The exclusion of the $\mathrm{Cv}$ and Max factors from Equation 8 resulted in the regression model expressed by Equation 9, whose adjusted coefficient of determination was $96,56 \%$, only $0,52 \%$ difference with the complete model, which reinforces the small influence of CV and Max factors.

$$
f_{c 0, k}(M P a)=-4,24+0,35 x_{m}+0,65 \operatorname{Min}\left[R^{2} a d j=96,56\right]
$$

Table 2 shows the ANOVA results of the regression model of Equation 9 and in Figure 2 the validation tests of the analysis of variance.

Table 2: Results of the ANOVA of the regression model of Equation 9.

\begin{tabular}{|c|c|c|c|c|c|}
\hline Source & GL & SQ (Aj.) & QM (Aj.) & F-Value & P-Value \\
\hline Regression & 2 & 11050,9 & 5525,47 & 618,15 & 0,000 \\
\hline $\mathrm{x}_{\mathrm{m}}$ & 1 & 646,3 & 646,30 & 72,30 & 0,000 \\
\hline Min & 1 & 1665,4 & 1665,40 & 186,31 & 0,000 \\
\hline Error & 42 & 375,4 & 8,94 & & \\
\hline Fault of adjust & 41 & 375,3 & 9,15 & 54,42 & 0,107 \\
\hline Pure Error & 1 & 0,2 & 0,17 & $*$ & $*$ \\
\hline Total & 44 & 11426,4 & & \multicolumn{1}{|l}{} \\
\hline
\end{tabular}

* GL - freedom degrees, $\mathrm{SQ}(\mathrm{Aj})$ - sum of squares; QM(Aj) - mean squares.

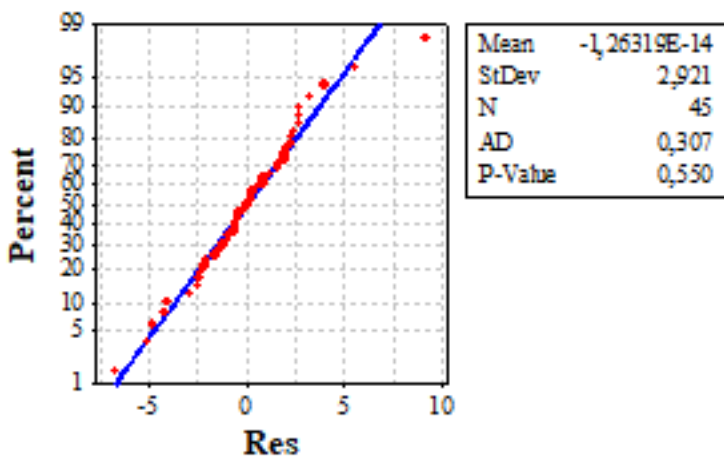

Figure 3: Anderson-Darling normality test of residues for ANOVA validation. 


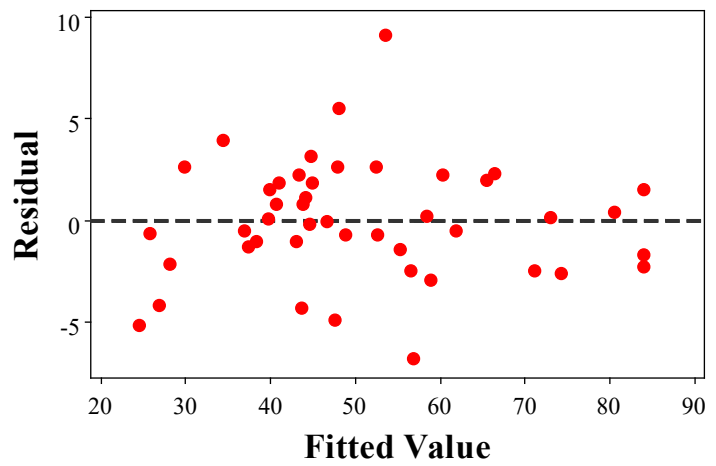

Figure 4: Residue graph versus adjusted values (b) for ANOVA validation.

The results of Figure 3 and Figure 4 show the validity of the ANOVA model, and from Table 2, it is evident that the two factors $\mathrm{x}_{\mathrm{m}}$ and Min are significant. Again, it is verified that the lack of adjustment is not significant and that the obtained model is significant.

The analysis of variance (at $5 \%$ level of significance) was also used as a way of comparing the results of the model proposed (Equation 9) with the results of the use of Equation 2 established by the Brazilian standard to obtain $f_{c o, k}$. Figure 5 shows the mean values and confidence intervals of the mean (at the $95 \%$ confidence level) of the values of $f_{c 0, k}$ obtained by both calculation methods, and Table 3 and Figura 6 shows the ANOVA results and validation, respectively.

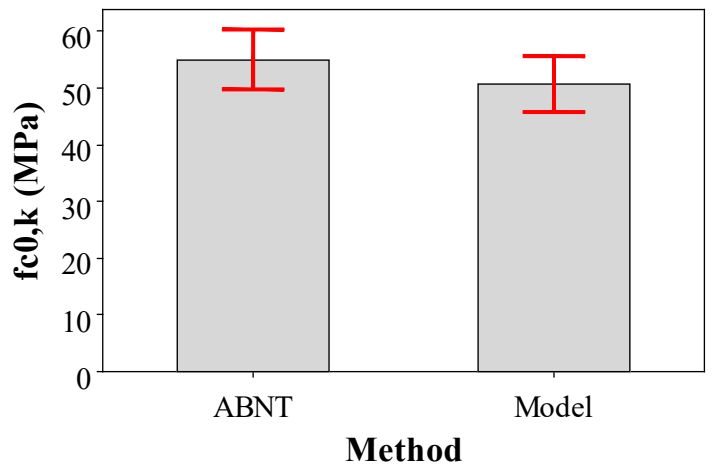

Figure 5: Mean values and confidence intervals for $\mathrm{f}_{\mathrm{c} 0 \mathrm{k}}$ obtained by both calculation methods.

Table 3: Result of ANOVA referring to the comparison of the models to obtain $f_{c 0, k}$.

\begin{tabular}{|c|c|c|c|c|c|}
\hline Source & GL & SQ (Aj.) & QM (Aj.) & Valor F & Valor-P \\
\hline Method & 1 & 413,9 & 413,9 & 1,48 & 0,227 \\
\hline Error & 88 & 24602,1 & 279,6 & & \\
\hline Total & 89 & 25016,0 & & & \\
\hline
\end{tabular}

* GL - freedom degrees, $\mathrm{SQ}(\mathrm{Aj})$ - sum of squares; $\mathrm{QM}(\mathrm{Aj})$ - mean squares. 


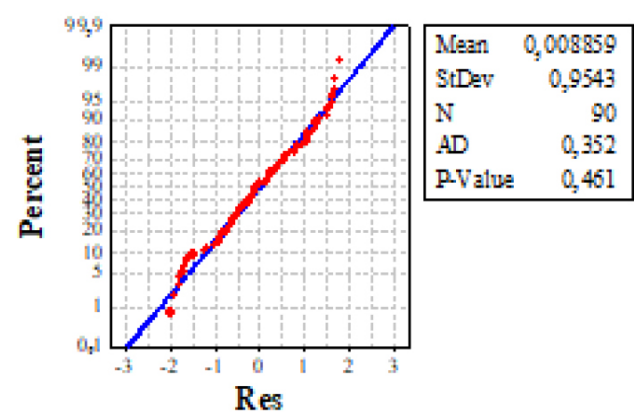

(a)

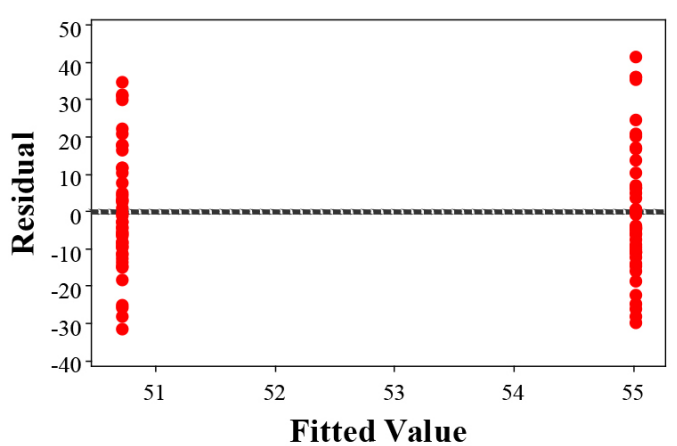

(b)

Figure 6: Validation of ANOVA between the models - Anderson Darling normality test (a) and graph of residuals versus adjusted values (b).

Based on the results of Table 3, the calculation model of the Brazilian standard and the regression model proposed in this research for estimating the values of $f_{c 0 . k}$ are statistically equivalent, even though the mean of the values of $f_{c 0, k}$ obtained by the regression model smaller when compared to the average of the values of $f_{c 0, k^{\prime}}$ coming from the standard model (Figure 5).

FromEquation9, itshouldbepointedoutthatforagivenspeciesofwood, theaveragevalue $\left(\mathrm{x}_{\mathrm{m}}\right)$ of $f_{c 0}$ and thelowest value of this property of the respective set of sample results, the characteristic value $\left(f_{c 0 . k}\right)$ can be easily determined, unlike the way of obtaining this property using the equation of the Brazilian standard (Equation 2), which initially requires the ordering and exclusion of part of the set of experimental results for later realization of the accounts.

To verify the accuracy of Equation 9, a new species of wood (Ipê Amarelo - Tabebuia spp., Bignoniaceae) was characterized in compression parallel to the grain. The average $f_{c 0}$ value for twelve specimens was equal to 81,73 MPa, and the lowest sample value obtained was 71,90 MPa. By Equation 2 of the Brazilian standard, the characteristic strength value resulted in $78,63 \mathrm{MPa}$. According to the probability distribution models considered, the one with the best adherence was Normal, with a characteristic strength value equal to $69,75 \mathrm{MPa}$. Using Equation 9, the characteristic strength value of the Ipê Amarelo wood was equal to 71,10 MPa. Considering the probability distribution model as a reference (of greater precision), the relative error made with the use of Equation 9 was 1,94 \%, which shows the excellent precision of the proposed alternative model.

\section{CONCLUSIONS}

The results of the regression model proposed here, with excellent accuracy ( $\mathrm{R}^{2}$ aj greater than $96 \%$ ) and dependent only on the mean and minimum value of the compressive strength parallel to the grain of the set of results, were statistically equivalent to the model proposed by the Brazilian standard, evidencing the good precision contained in the calculation model of this standard. However, the use of the regression model proposed in this research is justified for the ease in calculating the characteristic strength value and also for providing an accuracy, suitable to be incorporated in future versions of the Brazilian standard. 


\section{REFERENCES}

Almeida, T.H.; Almeida, D.H.; Christoforo, A.L.; Chahud, E.; Branco, L.A.M.N.; Lahr, F.A.R. 2016. Density as estimator of strength in compression parallel to the grain in wood. Int J Mat Eng 6(3): 67-71. http:// dx.doi.org/10.5923/j.ijme.20160603.01.

Andrade JR. J.R.; Almeida, D.H.; Almeida, T.H.; Christoforo, A.L.; Stamato, G.C.; Lahr, F.A.R. 2014. Avaliação das estruturas de cobertura em madeira de um galpão de estoques de produtos químicos. Amb Constr 14(3): 75-85. http://dx.doi.org/10.1590/S1678-86212014000300006.

Arruda, L.M.; Del Menezzi, C.H.S.; Andrade, A. 2015. Utilization of a thermomechanical process to enhance properties of a hardwood used for flooring. Braz J Wood Sci 6(3): 223-231. http://dx.doi.org/10.15210/ cmad.v6i3.7144.

Baar, J.; Tippner, J.; Rademacher, P. 2015. Prediction of mechanical properties - modulus of rupture and modulus of elasticity of five tropical species by nondestructive methods. Maderas. Ciencia y tecnologia 17(2): 239-252. http://dx.doi.org/10.4067/S0718-221X2015005000023.

Cavalheiro, R.S.; Almeida, D.H.; Almeida, T.H.; Christoforo, A.L.; Lahr, F.A.R. 2016. Density as estimator of shrinkage for some Brazilian Wood species. Int J Mater Eng 6(3):107-112. http://dx.doi. org/10.5923/j.ijme.20160603.08.

Chen, Y.; Guo, W. 2017. Nondestructive evaluation and reliability analysis for determining the mechanical properties of old wood of ancient timber structure. BioResources 12(2): 2310-2325. http://dx.doi.org/ 10.15376/biores.12.2.2310-2325.

Christoforo, A.L.; Aftimus, B.H.C.; Panzera, T.H.; Machado, G.O.; Lahr, F.A.R. 2017. Physico-mechanical characterization of the Anadenanthera columbrina Wood specie. Eng Agric 37(2): 376-384. http:// dx.doi.org/10.1590/1809-4430-eng.agric.v37n2p376-384/2017.

Ferro, F.S.; Icimoto, F.H.; Almeida, D.H.; Christoforo, A.L.; Lahr, F.A.R. 2015. Influência da posição dos instrumentos de medida na determinação do módulo de elasticidade da madeira na compressão paralela às fibras (E $\mathrm{E}_{\mathrm{c} 0}$ ). Rev Árvore 39(4): 743-749. http://dx.doi.org/10.1590/0100-67622015000400017.

Freitas, A.S.; Gonçalez, J.C.; Del Menezzi, C.H. 2016. Tratamento termomecânico e seus efeitos nas propriedades da Simarouba amara (Aubl.). FLORAM 23(4): 565-572. http://dx.doi.org/10.1590/21798087.144115.

Lahr, F.A.R.; Christoforo, A.L.; Varanda, L.D.; Araujo, V.A.; Chahud, E.; Branco, L.A.M.N. 2017. Shear and longitudinal modulus of elasticity in wood. relations based on static bending tests. Acta Sci-Tech 39: 433-437. http://dx.doi.org/10.4025/actascitechnol.v39i4.30512.

Minitab. 2017. Minitab software version 18. MINITAB, State College, PA, United States of America. https://www.minitab.com/.

Pinto, E.M.; Espinosa, M.M.; Calil JR, C. 2004. Métodos para Determinação do Valor Característico da Resistência à Compressão Paralela às Fibras da Madeira. Madeira: Arquitetura e Engenharia 5(14): 1-6. http:// madeira.set.eesc.usp.br/article/view/264.

Steege, H.; Vaessen, R.W.; Lopez, D.C.; Sabatier, D.; Antonelli, A.; Oliveira, S. M.; Pitman, N.C.A.; Jorgensen, P.M.; Salomão, R.P. 2016. The discovery of the Amazonian tree flora with an update checklist of all known tree taxa. Sci Rep 6(29549): 1-15. http://dx.doi.org/10.1038/srep29549. 
Weerahandi, S. 1995. ANOVA under Unequal Error Variances. Biometrics 51(2): 589-599. http://dx.doi. org/10.2307/2532947. 